\title{
When good times go bad: managing 'legal high' complications in the emergency department
}

This article was published in the following Dove Press journal:

Open Access Emergency Medicine

\section{Charles R Caffrey \\ Patrick M Lank}

Department of Emergency Medicine, Feinberg School of Medicine, Northwestern University, Chicago, IL, USA
Correspondence: Charles R Caffrey Department of Emergency Medicine, Feinberg School of Medicine,

Northwestern University, 2II E. Ontario St. Suite 200, Chicago, IL, 606 I I, USA

$\mathrm{Tel}+\mathrm{I} 3126947000$

Fax + I 3129266274

Email charliecaffrey@gmail.com

\begin{abstract}
Patients can use numerous drugs that exist outside of existing regulatory statutes in order to get "legal highs." Legal psychoactive substances represent a challenge to the emergency medicine physician due to the sheer number of available agents, their multiple toxidromes and presentations, their escaping traditional methods of analysis, and the reluctance of patients to divulge their use of these agents. This paper endeavors to cover a wide variety of "legal highs," or uncontrolled psychoactive substances that may have abuse potential and may result in serious toxicity. These agents include not only some novel psychoactive substances aka "designer drugs," but also a wide variety of over-the-counter medications, herbal supplements, and even a household culinary spice. The care of patients in the emergency department who have used "legal high" substances is challenging. Patients may misunderstand the substance they have been exposed to, there are rarely any readily available laboratory confirmatory tests for these substances, and the exact substances being abused may change on a near-daily basis. This review will attempt to group legal agents into expected toxidromes and discuss associated common clinical manifestations and management. A focus on aggressive symptom-based supportive care as well as management of end-organ dysfunction is the mainstay of treatment for these patients in the emergency department.
\end{abstract}

Keywords: legal highs, novel psychoactive substances, toxicology, opioid toxidrome, anticholinergic toxidrome, sympathomimetic toxidrome, hallucinogens, inhalants

\section{Introduction}

Much of the recent discussion on "legal highs" has focused on the so-called novel psychoactive substances (NPS), an ever-expanding group of chemicals known as designer drugs that has flooded the drug market in the past decade. ${ }^{1}$ These chemicals are creatively marketed and continuously re-designed to stay one step ahead of current regulatory legislation. ${ }^{1}$ However, the misuse of legal substances to produce hallucinogenic, stimulant, euphoric, or depressant effects akin to controlled substances has occurred since the earliest efforts at drug regulation. After the 1925 Geneva Opium Convention attempted to establish international control over morphine, drug manufacturers started flooding the market with uncontrolled morphine chemical derivatives. ${ }^{2}$ Furthermore, people seeking psychoactive effects akin to illicit substances have long turned to not only novel designer chemicals but also household products such as propylhexedrine-based inhalers, dextromethorphan (DXM)-based over-the-counter remedies, and nutmeg, to name only a few.

With this expanded definition in mind, this paper endeavors to cover a wide variety of "legal highs," or uncontrolled psychoactive substances that may have abuse potential 
and may result in serious toxicity. Throughout this paper, we recognize that the care of patients in the emergency department (ED) who have used "legal high" substances is challenging. Patients may misunderstand what the substance is they have been exposed to, there are rarely any readily available laboratory confirmatory tests for these substances, and the exact substances being abused may change on a near-daily basis. Recognizing these challenges we will attempt to group legal agents into expected toxidromes and discuss associated common clinical manifestations and management.

\section{Anticholinergic legal highs}

Producing the toxidrome of tachycardia, mydriasis, urinary retention, dry mucosal membranes, skin flushing, and hypoactive bowel sounds, anticholinergic agents have long been abused for their hallucinogenic, euphoric, and stimulant effects. ${ }^{3,4}$ The major legal sources of anticholinergic drugs of abuse include the over-the-counter agent diphenhydramine as well as the ubiquitous belladonna alkaloid plants. Included in this section are other legal highs such as nutmeg as well as the mushroom Amanita muscaria (aka "fly agaric"), which also cause anticholinergic-like toxicity.

\section{Belladonna alkaloid plants}

The belladonna alkaloids are atropine, hyoscyamine, and scopolamine, which are found in large concentrations in plants such as deadly nightshade (Atropa belladonna), Jimson weed (Datura stramonium), and moonflower (Datura inoxia). ${ }^{5}$ These plants grow widespread throughout North America. ${ }^{5}$ Due to their ubiquity and legality, these plants have found abuse potential for their hallucinogenic properties, typically among adolescents and young adults. ${ }^{6,7}$ Among the belladonna alkaloids, scopolamine is considered to mediate the plant's hallucinogenic effects, while atropine causes more peripheral effects. ${ }^{7}$ Ingestion of plant matter will result in marked adverse peripheral effects, including tachycardia and dry mouth, which often occur before the onset of their hallucinogenic effects. ${ }^{7}$

Belladonna alkaloid overdoses manifest as anticholinergic toxicity. ${ }^{7}$ Although fatalities have been reported from circulatory collapse and hypotension from belladonna alkaloids, ${ }^{5}$ they are rare in the setting of isolated ingestion. An analysis of 1458 cases reported to American poison centers revealed no attributable fatalities. ${ }^{8}$ Another series of 8 years of poison center data only found 5 reported fatalities attributable to Datura. ${ }^{7}$ Notably, Datura ingestions may present with prolonged toxic effects lasting hours to days, given the half-lives of 2-3 hours for atropine and up to 9-10 hours for scopolamine combined with decreased gastrointestinal (GI) motility. ${ }^{7}$
In addition to supportive care, management of belladonna alkaloid plant toxicity centers around treating agitation as well as reversing severe anticholinergic effects if needed. Decontamination with activated charcoal is controversial, as most patients will present for medical care when clinically intoxicated and agitated. ${ }^{7}$ For cases of minor toxicity, benzodiazepines are one mainstay of supportive care. ${ }^{7}$ For severe agitation, the cholinesterase inhibitor physostigmine is effective in reversing isolated anticholinergic toxicity. ${ }^{7}$ Due to the risk of triggering a cholinergic crisis, including bradycardia, respiratory distress and seizures, physostigmine should be used with caution, and only with a reversal agent such as atropine on hand. ${ }^{7}$ The starting dose of physostigmine is $0.5-2 \mathrm{mg}$ in adults infused intravenously no faster than $1 \mathrm{mg} /$ minute, with redosing occasionally necessary because of the drug's relatively short half-life of 15-40 minutes. ${ }^{7}$

\section{Diphenhydramine}

Diphenhydramine (Benadryl ${ }^{\circledR}$, Johnson \& Johnson, New Brunswick, NJ, USA) is a histamine blocker with central effects as well as anticholinergic and sodium channel blocking properties, found in many over-the-counter medications ranging from sleep aids to allergy and cold medications. ${ }^{3}$ Although thought to have limited abuse potential due to its overly sedating qualities, diphenhydramine is, in fact, commonly abused for its euphoric and hallucinogenic effects at higher dosages. ${ }^{3,9,10}$ Diphenhydramine is commonly co-formulated with acetaminophen, and in cases of toxic overdoses, the delayed GI motility from diphenhydramine can contribute to delayed and persistent toxic levels of acetaminophen. ${ }^{11}$

The classic signs of diphenhydramine overdose are an anticholinergic toxidrome combined with profound sedation and at times marked agitation. ${ }^{12}$ Diphenhydramine has also been known to produce rhabdomyolysis. ${ }^{13}$ Also, in comparison with other anticholinergics, diphenhydramine is much more likely to cause seizures in acute overdose. ${ }^{14}$ Diphenhydramine is chemically similar to the tricyclic antidepressants and has sodium channel blockade effects resulting in seizures and wide complex tachyarrhythmias in higher dosages. ${ }^{15}$

Management of diphenhydramine toxicity centers around control of agitation and hyperthermia, as well as treating rhabdomyolysis, potential tachyarrhythmias, and seizures. ${ }^{16}$ Although physostigmine has a role in reversing anticholinergic effects, it is contraindicated in cardiotoxic diphenhydramine overdoses due to the risk of asystole, and should not be used if the QRS $>100 \mathrm{~ms}$ in the setting of a diphenhydramine overdose. ${ }^{17}$ In case of QRS widening or 
tachyarrhythmias, sodium bicarbonate has been used successfully. ${ }^{15}$ Massive overdoses due to diphenhydramine with refractory tachyarrhythmias have been treated successfully with intralipid therapy. ${ }^{18}$

\section{Nutmeg}

Widely available, nutmeg is known to provoke hallucinogenic effects in high dosages. According to available case reports, nutmeg reached a peak of abuse in the 1960s and 1970s. ${ }^{19}$ It is well documented as a drug of abuse among prisoners, with Malcolm X famously detailing in his autobiography during his incarceration that a "a penny matchbox full of nutmeg had the kick of 3 or 4 reefers." ${ }^{20}$ Most likely due to unpleasant, dysphoric side effects as well as need to consume a large unpalatable amount, nutmeg abuse is not common among the general population. ${ }^{21-23}$

Nutmeg's intoxicating effects are thought to be due to myristicin, the largest chemical portion of the volatile oil of nutmeg. ${ }^{24}$ Myristicin acts as a monoamine oxidase inhibitor (MAOI), increasing the amount of serotonin in the brain. ${ }^{25}$ It has also been found in animal models to be metabolized into 3-methoxy-4,5-methylene dioxyamphetamine, which is a sympathomimetic with hallucinogenic and euphoric effects. $^{26}$

Nutmeg produces a biological effect similar to an anticholinergic toxidrome, with altered mental status, skin flushing, dry mucus membranes, tachycardia, and hypertension. ${ }^{24} \mathrm{~A}$ feature to distinguish nutmeg toxicity from an anticholinergic agent is miosis, although a large amount of nutmeg intoxications with mydriatic pupils have been noted in 1 case series. ${ }^{27}$ Treatment for nutmeg intoxications is supportive in nature. ${ }^{24}$ One case series reported a provoked seizure in the setting of nutmeg intoxication in a person with a seizure disorder. ${ }^{23}$ Only 2 fatalities are known in the literature, with both cases being notable for myriad confounding variables. ${ }^{22}$ One regional survey found that nutmeg was commonly associated with concurrent drug exposures. ${ }^{23}$

\section{A. muscaria}

A. muscaria aka "fly agaric" is a mushroom that grows near pine trees throughout the northern hemisphere, identifiable by its bright red caps with white spots (Figure 1). ${ }^{28}$ Legal to possess and consumed for its hallucinogenic properties, the main psychoactive components of fly agaric are ibotenic acid, an analog of the excitatory neurotransmitter glutamate, as well as muscimol, an analog of the inhibitory neurotransmitter gammaAminobutyric acid (GABA) ${ }^{29}$ These contradictory chemicals are thought to result in a subjective experience similar to alcohol

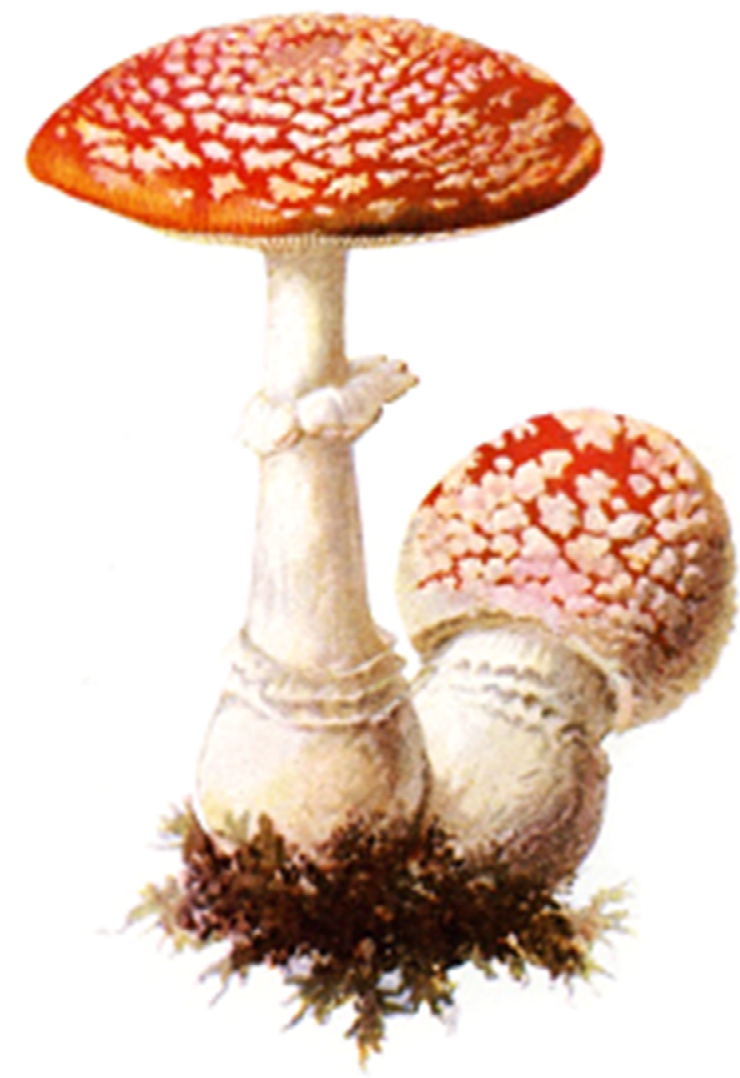

Figure I Amanita muscaria

intoxication due to GABA-like effects, but with hallucinations due to its concurrent glutamate-like effects. ${ }^{30}$

The clinical toxidrome of fly agaric has been said to mimic that of an anticholinergic toxidrome, with flushing, fever, and pupillary dilation..$^{28,31}$ Vomiting and diarrhea have also been reported, ${ }^{31}$ although some sources report this to be an infrequent feature of fly agaric intoxication. ${ }^{28}$ Termed "pantherine-muscarine" poisoning, the neurologic effects of fly agaric mimic its concurrent GABA and glutamate analog components, with sometimes rapid alternation between profound sedation and severe agitation. ${ }^{31}$

Treatment is supportive, with consideration of GI decontamination with charcoal. ${ }^{28}$ Benzodiazepines can be used for adverse excitatory effects such as seizures, but with caution, given potential rapid switching to muscimol-mediated sedation. ${ }^{28}$ Effects can last up to 24 hours, and fatalities are rare. ${ }^{28}$ Also, concurrent ingestions should be considered, including accidental ingestion of the more hepatotoxic cyclopeptidecontaining mushrooms such as Amanita phalloides. ${ }^{30}$

\section{Opioid legal highs}

As the USA grapples with unprecedented levels of opioid abuse, there has been an increased push among prescribers 
and regulatory bodies to curb long-term prescribing of these medications. ${ }^{32}$ Opioid-dependent patients seeking to reduce prescription opioid use, or those who have had their prescription sources curtailed by medical providers, have increasingly turned to legally available opioid substitutes to provide euphoric effects as well as to mitigate withdrawal symptoms. ${ }^{33}$ Legal substances that have emerged as opioid substitutes include loperamide, kratom, poppy seed tea (PST), and a number of synthetic designer opioids.

\section{Loperamide}

Loperamide Imodium $^{\circledR}$, Johnson \& Johnson, New Brunswick, NJ, USA) is a peripherally acting opioid derivative used as an over-the-counter antidiarrheal since $1988 .{ }^{34}$ Long considered a drug with low abuse potential, its central penetration is thought to be limited by overall poor bioavailability as well as the action of P-glycoproteins that actively secrete the drug from the central nervous system. ${ }^{35}$ After many years of only scattered reports of toxicity and abuse, loperamide has recently emerged as a drug of abuse in the USA, largely going hand-in-hand with the opioid epidemic. ${ }^{35}$ Known as the "desperate junky's methadone," it is mainly abused to alleviate withdrawal symptoms, and by some to provoke an opioid-based euphoria. ${ }^{36}$ Abusers of loperamide typically take 3-4 times the recommended daily dose in 1 sitting. ${ }^{35}$ Some also take advantage of cytochrome inhibitors such as cimetidine and grapefruit juice as well as P-glycoprotein inhibitors such as quinidine and pepper to raise serum levels of the drug. ${ }^{35}$

Loperamide's main toxic effects include not only the respiratory and central nervous system depression typical of opioid overdoses, but also cardiotoxicity in the form of life threatening cardiac arrhythmias. ${ }^{35}$ Loperamide in high doses has been found to have sodium and potassium channel blocking effects, resulting in profound cardiotoxic effects. ${ }^{37}$ It has been associated with widening of the QRS complex, prolonged QTc interval, as well as ventricular monomorphic and polymorphic tachycardias resulting in multiple fatalities. ${ }^{37,38}$ Syncope or ventricular dysrhythmias and electrocardiogram abnormalities in a patient suspected of opioid abuse should trigger consideration of loperamide toxicity. ${ }^{37}$ Loperamide will not show up on a standard urine drug screen. ${ }^{35}$

Management of loperamide toxicity includes extended consideration of decontamination, treatment of respiratory depression, and monitoring and treatment of potential cardiotoxicity. ${ }^{37}$ Charcoal-based GI decontamination has been advised up to 2-4 hours after a large overdose in the absence of contraindications, due to the drug's GI motility slowing effects. ${ }^{37}$ Naloxone has been used for loperamide-provoked respiratory depression, with one pediatric case needing multiple doses over a 24-hour period, presumably due to the drug's slow elimination times. ${ }^{35}$ Widened QRS complexes due to loperamide may be reasonably treated with sodium bicarbonate, while long QT intervals should be treated with correction of electrolyte derangements. ${ }^{35}$ It is reasonable to treat loperamide-induced torsades with standard agents, including magnesium, defibrillation, isoproterenol, and electrical pacing. ${ }^{37}$

\section{Poppy seed tea}

Although opium and the poppy plant itself are controlled in the USA, poppy seeds are completely unregulated and can be bought in bulk. Although they do not contain any psychoactive opiates, poppy seeds have been shown to have trace amounts of opium latex containing morphine and codeine on their surface. ${ }^{39}$ This fact has been exploited by those seeking a legal and readily accessible source of opiates by making poppy seed tea (PST). ${ }^{40}$ PST synthesis involves steeping a bulk supply of poppy seeds in water, thus diluting a variable amount of codeine and morphine into a liquid that is then ingested. ${ }^{40}$ PST abuse emerged among opiate-dependent patients in New Zealand after a government crackdown on heroin supply to the country. ${ }^{40}$ The internet provides both a means of purchasing bulk poppy seeds as well as a source of information on PST use and instructions for preparation. ${ }^{40}$ The main limitation on PST use among some users was its foul taste. ${ }^{40}$ Users have reported an onset of 15 minutes and sometimes prolonged effects lasting up to 24 hours. ${ }^{40}$

Although official case reports of fatalities are sparse, scattered fatalities in the popular media have been reported among young people using PST. ${ }^{41}$ Cases of physiologic dependence on poppy seed concoctions have also been reported. ${ }^{42}$ An issue with the synthesis of PST is the highly variable opiate content found among different seed sources, ranging from 1-2 orders of magnitude for morphine and codeine content based on seed source. ${ }^{39}$ This may make it very difficult for those synthesizing and ingesting opiates by this method to reliably ascertain the morphine and codeine content of their PST, theoretically leading to the potential for overdose.

\section{Kratom}

Kratom is the common name for the plant Mitragyna speciosa, a large leafy tree which is indigenous to Southeast Asia, containing psychoactive alkaloids with dose-dependent stimulatory and opioid-like effects. ${ }^{43}$ By way of direct chewing of leaves or through the formation of teas and other mixtures, kratom has been traditionally used throughout Southeast Asia as an antidi- 
arrheal, a painkiller, and a cheap opium substitute. ${ }^{43}$ Kratom has emerged in the USA as an easily available and legal opioid substitute, available through internet suppliers as well as brickand-mortar "smoke shops," with the number of calls to poison centers regarding kratom increasing from 26 in 2010 to 263 in 2015. ${ }^{44}$ In late 2016, the Drug Enforcement Administration (DEA) attempted to classify kratom and its main psychoactive alkaloids mitragynine and 7-hydroxymitragynine as Schedule I substances, a move that was met with such fierce public backlash that the agency backed down from their scheduling decision pending further review in October 2016. ${ }^{45}$

Kratom's main psychoactive alkaloids are mitragynine and 7-hydroxymitragynine, substances that have been shown to have activity at supraspinal $\mu$-opioid receptors, as well as possible stimulant activity through alpha- 2 receptors and $5-\mathrm{HT}_{2 \mathrm{~A}}$ receptors. ${ }^{44}$ Kratom users commonly report a dosedependent response with stimulant effects in small doses up to opioid analgesic effects in higher doses.$^{46}$ Other subjective effects include euphoria, relaxation, increased energy, with some negative effects, including nausea, vomiting, stomach ache, and constipation. ${ }^{44}$

The safety profile of kratom has not been fully evaluated. Well-controlled data on the toxic effects of kratom on human subjects are lacking, and case reports of toxicity are relatively rare. There have been scattered case reports of intractable seizures that are refractory to benzodiazepines in patients with acute kratom ingestions, although many cases are associated with co-ingestion of other prescription and illicit drugs. ${ }^{44}$ Regarding their tendency to produce opioid toxicity, animal models have generally found less respiratory depression with mitragynine compared with other opioid receptor agonists, ${ }^{47}$ and there has not yet been a case report of kratom inducing an opioid-based hypoventilatory state in which naloxone has been used. However, it would be reasonable to give naloxone in the setting of a kratom ingestion with respiratory depression. Kratom has been frequently adulterated with other opioid receptor agonists such as $O$-desmethyltramadol, resulting in 9 deaths in 1 case series. ${ }^{48}$ Long-term use of kratom has been associated with intrahepatic cholestasis and other liver disease, along with hypothyroidism. ${ }^{44}$ Patients can also develop physical dependence with withdrawal symptoms that mimic that of opioids, with symptoms such as abdominal pain, sweatiness, nausea, vomiting, and diarrhea. ${ }^{147}$ There have been reports of fatalities with high levels of mitragynine, with kratom presumably as the cause of death, but these reports are also notable for many other co-ingestions such as propylhexedrine, benzodiazepines, and selective serotonin reuptake inhibitors (SSRIs) ${ }^{49,50}$

\section{Synthetic opioids}

In tandem with the opioid epidemic, synthetic designer opioids such as AH-7921, U-47700, MT-45, and numerous fentanyl (Sublimaze ${ }^{\circledR}$, Janssen Pharmaceutica, Beerse, Belgium) analogs have emerged onto the drug market in the past few years. In an effort to stem the flood of these agents, the DEA has continuously added synthetic opioids to Schedule I, including U-47700, AH-7921, and many fentanyl analogs. Still unscheduled, an opioid known as MT-45, a piperazine derivative, has found abuse as a legally available opioid. ${ }^{51}$ MT-45 overdose produces an opioid toxidrome, and acute ingestions resulting in respiratory depression have been successfully reversed with naloxone. ${ }^{52}$ Users of MT-45 find it to have less opioid-euphoric effects at a relatively higher financial cost and with more adverse effects, likely putting a limit to its potential as a major drug of abuse. ${ }^{52}$ Adverse effects unique to habitual MT-45 abuse include hair loss, hearing loss, dermatitis, and cataracts. ${ }^{51}$

A more substantial public health threat than MT-45 is the re-emergence of fentanyl and a wide range of fentanyl analogs to the illicit drug market. The abuse of fentanyl and novel fentanyl analogs dates to the 1970s, marketed in pure form such as 3-methylfentanyl being sold as "China White," but also as surreptitious additions to traditional illicit drugs such as heroin and cocaine ${ }^{53}$ Periodic epidemics of fentanyl abuse has resulted in sporadic outbursts of morbidity and mortality over the past few decades..$^{53}$ In 2016 alone, the DEA saw the use of 13 different fentanyl analogs on the illicit drug market, some of which are unscheduled. ${ }^{54}$ Fentanyl analogs vary widely in potency compared with morphine, ranging from acetylfentanyl, which is 15.7 times as potent, up to 3-methylfentanyl, which may be 569 times as potent. ${ }^{53}$ A major consideration for the emergency medicine provider is that overdoses of fentanyl and the more potent fentanyl analogs may require substantially more naloxone than that of heroin for their reversal, up to $12 \mathrm{mg}$ in a case series from Illinois. ${ }^{55}$

\section{Sympathomimetic legal highs}

There are many "legal highs" that result in a sympathomimetic toxidrome. Many of them are abused by those seeking similar effects as the classic illicit psychostimulants such as cocaine, methamphetamine, and 3,4-methylenedioxy-Nmethylamphetamine (MDMA). Others are abused for their serotonin-mediated hallucinogenic effects, but are notable for producing sympathomimetic toxicity. Many of these agents will share similarities in their treatment approach, which entails benzodiazepines, active cooling for hyperthermia, and 
specific management of end-organ complications related to hypertension and vasoconstrictive effects.

\section{Synthetic cathinones}

A Schedule I substance, cathinone is a monoamine amphetamine analog with stimulatory properties found in the shrub Catha edulis, commonly known as khat. ${ }^{56}$ Khat is endemic to the Horn of Africa as well as the Southeast Arabian peninsula, where it is only chewed fresh for its stimulatory effects due to cathinone's quick degradation. ${ }^{56}$ Since cathinone's discovery, many chemical derivatives have been synthesized and researched for possible therapeutic effects, the most successful of which is the antidepressant bupropion (Wellbutrin ${ }^{\circledR}$, GlaxoSmithKline, Brentford, UK) ( $m$-chloro- $N$-tert-butyl-cathinone). ${ }^{56}$

In the past decade, many synthetic cathinones have been developed and exploited for their strong stimulant effects as "not for human consumption" legal highs, marketed as "bath salts" or "plant food." ${ }^{56}$ When consumed, these substances have variable stimulatory effects comparable with methamphetamine or MDMA. ${ }^{57}$ Cathinone and mephedrone do share chemical structural similarities with methamphetamine (Figure 2). Synthetic cathinones reached a peak of 6137 reports in 2012 , declining to 382 in $2016,{ }^{58}$ likely due to federal and state efforts at scheduling and regulating these psychoactive substances. ${ }^{59}$ Following a pattern of other NPS, new agents continue to be synthesized and marketed outside federal control according to the DEA's Emerging Threat Report. ${ }^{54}$

The toxicologic effects of synthetic cathinones mimic those of the amphetamines as well as MDMA, and treatment is primarily supportive around managing the agitation, fever, hyponatremia, and end-organ complications that can sometimes occur with these agents. ${ }^{57}$ Full evaluation of the toxicologic effects of cathinones is complicated by the breadth and emergence of new agents, as well as the common presence of co-ingestions. ${ }^{57}$ Notably, the main adverse effects include both cardiovascular (hypertension, tachycardia, angina, myocarditis) and neuropsychiatric (agitation, aggression, dystonia, and hyperreflexia) complications. ${ }^{57}$ There have been a number of case reports of hyponatremia in the context of using these agents, sometimes resulting in cerebral edema and death. ${ }^{57}$ Hyponatremia in the context of synthetic

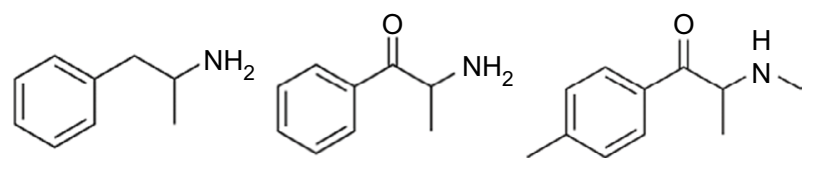

Figure 2 Chemical similarity of amphetamine, cathinone, and mephedrone; note the addition of the ketone functional group to the latter two compounds. cathinone use should be managed much like MDMA-related hyponatremia, with fluid restriction for mild cases up to the use of hyperosmotic agents for cerebral edema. ${ }^{57}$ Other noted laboratory abnormalities include metabolic acidosis, elevated creatinine kinase, elevated liver enzymes, and acute renal failure. ${ }^{57}$

\section{Benzofurans}

Commonly known as "Benzo Fury," the benzofurans refer to the phenethylamine MDA (3,4-methylenedioxyamphetamine) derivatives 5-(2-aminopropyl)benzofuran (5-APB) and 6-(2-am-inopropyl)benzofuran (6-APB), currently unscheduled chemicals abused for their stimulant as well as entactogenic effects similar to the Schedule I substance MDMA. ${ }^{60}$ Benzofurans have been found to inhibit reuptake of serotonin, dopamine, and norepinephrine, and they also have affinity for adrenergic and 5-HT receptors. ${ }^{60}$

The subjective effects of benzofurans have been described as much like MDMA, but with more adverse effects in the form of nausea, dry mouth, dry eyes, insomnia, diarrhea, palpitations, headache, and various adverse psychological symptoms, including visual and auditory hallucinations. ${ }^{60}$ The benzofurans have also been shown to have extended persistence of clinical effects, lasting for more than 48 hours in over half of reported cases. ${ }^{60}$

Like many of the NPS, detailed toxicological information on the benzofurans are lacking, and acute ingestions are often concurrent with other intoxicants. ${ }^{61}$ Case reports point to dramatic sympathomimetic symptoms, including tachycardia, hypertension, mydriasis, hyperthermia, agitation, and tremors after ingestion of benzofurans. ${ }^{60}$ There have also been reports of myocardial ischemia, indicating perhaps more profound vasoconstrictive effects than MDMA. ${ }^{62}$ These substances have been implicated in more than 10 deaths. ${ }^{60}$ Management involves supportive care for sympathomimetic toxicity with benzodiazepines, as well as assessment for hypertensive emergency and rhabdomyolysis.

\section{Benzodifurans: Bromo-DragonFLY, 2C-B-FLY, 3C-B-FLY}

The benzodifurans, commonly known as the BromodragonFLY compounds, refer to a relatively novel group of hallucinogenic drugs that saw escalating amounts of abuse as legally available research chemicals over the past decade. ${ }^{63}$ They exert their potent hallucinogenic effects through $5-\mathrm{HT}_{2 \mathrm{~A}}$ agonism and serotonergic release. ${ }^{64}$ Its first member and archetype is Bromo-dragonFLY, an amphetamine derivative in which the phenyl group is buttressed by 2 dihydrofuran 
rings that give the compound its characteristic "dragonfly" shape as well as purported greater potency and duration of action than many other hallucinogenic phenethylamines (Figure 3) ${ }^{63}$ Its subjective effects have been described as akin to lysergic acid diethylamide (LSD), although onset may be delayed up to 6 hours, and effects may last up to 3 days. ${ }^{1}$

Case reports indicate that Bromo-dragonFLY compounds have potent sympathomimetic and vasoconstrictive toxicity. ${ }^{1}$ Clinical presentations of Bromo-dragonFLY ingestions seeking medical care are notable for sympathomimetic toxidromes in the form of tachycardia, hypertension, mydriasis, diaphoresis, agitation, and seizures. ${ }^{64,65}$ Seizure onset can be delayed, up to 8 hours after ingestion in one case.$^{66}$ There have also been cases of extended and refractory vasoconstriction lasting days after overdoses, resulting in auto-amputation of digits, renal failure, and rhabdomyolysis. ${ }^{67}$ Deaths have been attributed to the drug, including fatalities caused by massive overdoses in Oklahoma that occurred after BromodragonFLY was mistaken for the less potent derivative compound 2C-B-FLY. ${ }^{65,68}$

Bromo-dragonFLY overdose treatment is supportive. ${ }^{1}$ Sympathomimetic effects and seizures have been treated successfully with large and repeated doses of benzodiazepines. ${ }^{64}$ The drug's purported severe vasoconstrictive effects have proven refractory to a wide variety of vasodilatory therapies in available case reports. ${ }^{64}$

\section{Propylhexedrine}

A longstanding "legal high," abused due to its relatively low cost and widespread availability, propylhexedrine (Benzedrex $^{\circledR}$, B.F. Ascher \& Co., Inc., Lenexa, KS, USA) is a cyclohexylamine nasal decongestant that is chemically similar to methamphetamine, lacking the aromatic ring (Figure 4) ${ }^{69}$ Delivered via an over-the-counter nasal inhaler, propylhexedrine's mechanism as a nasal decongestant is through alpha adrenergic stimulation, resulting in localized vasoconstriction

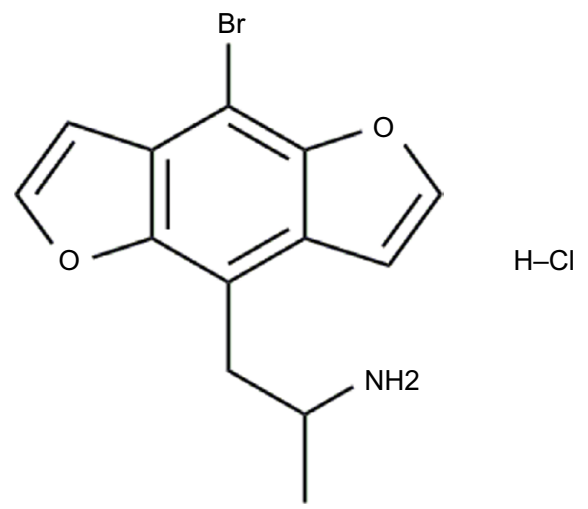

Figure 3 Chemical structure of Bromo-dragonFLY, demonstrating the dual dihydrofuran rings.
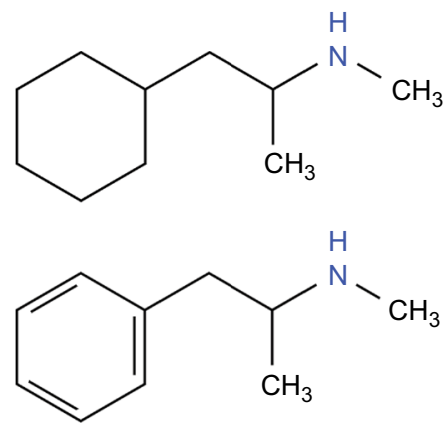

Figure 4 The single chemical difference between propylhexedrine (top) and methamphetamine (bottom) is the aromatic ring.

of the nasal mucosa. ${ }^{69}$ In higher doses, it also causes release of dopamine, norepinephrine, and serotonin from presynaptic vesicles much like the amphetamines. ${ }^{70}$ Since its introduction as a safer replacement of previous amphetamine-based inhalers, propylhexedrine has emerged as a legal substitute for methamphetamine. ${ }^{71}$ It is commonly abused by dismantling the inhaler and either ingesting the drug-soaked cotton rods whole, or by soaking the rod in lemon water and injecting or consuming the liquid. ${ }^{71}$ Its toxic effects reflect the fact that it is, compared with amphetamine, relatively more effective at promoting peripheral adrenergic stimulation rather than dopaminergic and serotonergic release. ${ }^{70}$

Toxicity of propylhexedrine mimics that of the amphetamines, but with seemingly more profound end-organ complications from its relatively higher hypertensive and vasoconstrictive effects, especially with intravenous injection. Clinical toxicity presents with a sympathomimetic-like toxidrome but with profound tachycardia and hypertension. ${ }^{69}$ The case literature is littered with examples of significant end-organ damage from propylhexedrine's peripheral effects, including cardiogenic shock and pulmonary edema in a 22-year-old who suffered a large anterior myocardial infarction, as well as cases of brainstem dysfunction characterized by ophthalmoplegia. ${ }^{72,73}$ One case series from Texas details an association between propylhexedrine injection and 15 cases of sudden death. ${ }^{74}$ Management of propylhexedrine toxicity centers around management of sympathomimetic toxicity and careful attention to and treatment of possible end-organ damage from its marked hypertensive effects.

\section{Mescaline}

Mescaline is a serotonergic phenethylamine hallucinogen most famously found in peyote, a small spineless cactus found in the deserts between the USA and Mexico that has been traditionally consumed by Native American tribes. ${ }^{75}$ Although mescaline and peyote itself are Schedule I substances, other mescaline-producing cacti such as San Pedro cactus and Peruvian Torch cactus are not controlled, and can be legally 
obtained through horticultural suppliers. ${ }^{30}$ Mescaline is a relatively rare drug of abuse, accounting for only 63 total exposures reported to USA poison control centers in $2015 .^{76}$

Mescaline is chemically related to amphetamines, and cases of toxicity produce a sympathomimetic-like toxidrome. ${ }^{75}$ Sympathetic symptoms such as mydriasis, tachycardia, and agitation are commonly seen. ${ }^{75}$ Despite its sympathomimetic effects in overdoses, life threatening toxic effects are rare. ${ }^{75}$ In 1 case series, GI symptoms were found to predominate, with marked abdominal pains, diarrhea, and vomiting that led medical providers to misdiagnose 1 ingestion as a possibly surgical abdomen. ${ }^{77}$ Management of mescaline intoxication is like that for many other hallucinogens: low stimulation environment and benzodiazepines with supportive care as needed..$^{75}$

\section{Dissociative legal highs}

$\mathrm{N}$-methyl-D-aspartate (NMDA) receptor antagonists such as phencyclidine (PCP) and ketamine are abused in recreational settings for their dissociative effects. Ketamine was officially scheduled in $1999,{ }^{78}$ and in the decade to follow the recreational drug market saw the synthesis and emergence of legal ketamine analogs such as methoxetamine and others. Furthermore, the over-the-counter cough remedy DXM has long been abused for its dissociative effects.

\section{Methoxetamine, Diphenidine, 2-Methoxydiphenidine}

Methoxetamine, an analog of ketamine that has NMDA antagonist activity, has been marketed via the internet as a legal high, and oftentimes as a safer alternative to ketamine abuse. ${ }^{79}$ After many European countries moved to ban the drug in the last 5 years in response to reports of fatalities, methoxetamine was then quickly joined by a flood of other "research chemicals" with dissociative properties, such as diphenidine, 2-methoxydiphenidine, as well as PCP analogs such as 3-methoxy-PCP and 4-methoxy-PCP. ${ }^{80,81}$ Many of these agents have not been fully described in terms of their exact pharmacologic and toxic properties, but given their subjective dissociative effects, they are presumed to be potent NMDA antagonists. ${ }^{82}$ Methoxetamine is ingested orally or absorbed sublingually, but can also be insufflated or even injected intramuscularly and intravenously. ${ }^{83}$ Methoxetamine presents clinically with dissociative effects as well as sympathomimetic effects, including tachycardia and hypertension. ${ }^{83}$

Much of the morbidity of methoxetamine and other novel dissociative psychoactive substances seem to be centered around their neurocognitive effects as well as sympathomi- metic qualities and propensity to be taken with other stimulatory psychoactive substances. ${ }^{84}$ Management is supportive, with benzodiazepines and intravenous (IV) fluids. ${ }^{83}$ Reports of diphenidine and methoxydiphenidine intoxications in Europe were noted to have a high percentage of co-ingestion with cannabis as well as other substances, resulting in severe intoxications. ${ }^{84}$ Patients commonly presented with hypertension, tachycardia, anxiety, and altered mental status requiring supportive care with benzodiazepines and sometimes propofol ${ }^{84}$ A high proportion of the 20 reported deaths due to methoxetamine intoxication were also notable for numerous co-ingestions of illicit as well as other legal NPS..$^{85}$

\section{Dextromethorphan}

DXM is a selective $\sigma$ receptor agonist that has been used for many decades in the USA as an over-the-counter cough remedy. ${ }^{86}$ Since its introduction in the 1950 s, DXM preparations have been abused for hallucinogenic and dissociative effects at high doses, a fact that led to its brief removal from the market in the 1970s and reformulation into worse-tasting compounds thought to have less abuse potential. ${ }^{87,88}$ Akin to many other legal highs, teenagers and young adults comprise the highest proportion of DXM abusers, among whom DXM abuse is known as "robotripping." " containing over-the-counter formulations can also exhibit signs of toxicity from coformulatory compounds, including hepatotoxic effects from acetaminophen, anticholinergic effects from diphenhydramine, depressant effects from ethanol, and sympathomimetic effects from pseudoephedrine. ${ }^{89,91}$ Those who wish to abuse DXM in purer forms can chemically extract it from over-the-counter preparations, as well as buy pure powder legally from online chemical distributors. ${ }^{92,93}$

DXM ingestion produces dissociative effects through its metabolism by cytochrome CYP2D6 to dextrorphan, an NMDA antagonist similar to PCP and ketamine. ${ }^{90}$ Like other dissociative agents, dextrorphan is also thought to exert adrenergic effects by inhibiting peripheral and central catecholamine reuptake. ${ }^{94}$ Further, as an isomer of the opioid levorphanol, DXM at high doses can affect opioid receptors, resulting in signs of opioid toxicity, including respiratory depression and miosis. ${ }^{89,95}$

The subjective effects of DXM abuse have been noted to entail 3 dose-dependent plateaus, with low doses producing mild stimulant and euphoric effects, middle doses producing an effect like concurrent alcohol and marijuana intoxication, and large doses producing a dissociative effect like ketamine or PCP intoxication. ${ }^{94,96}$ Clinically, presentations of DXM ingestions largely depend on the dose ingested, producing mainly effects on the central nervous system, including 
restlessness, lethargy, ataxia, slurred speech, as well as hyperreflexia. ${ }^{97}$ Patients can also present with sympathomimetic effects, including diaphoresis and hypertension. ${ }^{97}$ Effects on the ophthalmologic exam produce varying results, including everything from rotary nystagmus and mydriasis to the miosis seen in opioid ingestions. ${ }^{97}$ Onset of symptoms usually occurs 30 to 60 minutes after ingestion, and will persist for an average of 6 hours, making any asymptomatic presentation 4 hours post-ingestion at very low risk of later developing toxicity. ${ }^{89}$

The major toxic effects of DXM are managed with supportive care, and are centered around benzodiazepines for acute agitation, management of toxicity from coformulatory agents, as well as possible serotonin syndrome. ${ }^{89}$ Guidelines also promote the use of activated charcoal up to 1 hour after the reported time of ingestion. ${ }^{89}$ It is reasonable to give naloxone to comatose or bradypneic patients in whom DXM ingestion is suspected, as opioid effects or opioid co-ingestants may be present. ${ }^{89}$ Long-term DXM abuse has produced cases of physical dependence in which abrupt cessation of the drug results in physical withdrawal symptoms of vomiting, myalgias, diarrhea, and night sweats. ${ }^{89}$

A major concern with DXM ingestion, even at therapeutic dosages in concert with certain other serotonin-affective drugs, is the risk of serotonin syndrome. There have been cases of serotonin syndrome when DXM was taken at antitussive therapeutic dosages in patients on therapeutic MAOIs such as phenelzine, as well as selective serotonin reuptake inhibitors such as fluoxetine. ${ }^{89}$ Such presentations should be managed aggressively with IV fluids, benzodiazepines, and active cooling measures. ${ }^{89}$

As DXM is commonly found in bromide salt, there have been theoretical concerns that massive ingestions will result in bromide toxicity as well as false elevations of chloride and even negative anion gaps due to misidentification of bromide for chloride by laboratory autoanalyzers. However, the only available evidence of bromism in the form of elevated chloride and a low (or negative) anion gap in the context of DXM use comes from a single case report. ${ }^{98} \mathrm{~A}$ more recent case report of DXM-related clinical bromism occurred when DXM was used with an older bromide-containing pharmaceutical. ${ }^{99}$

\section{Hallucinogenic and other compounds}

There are many legal hallucinogenic compounds that lack a discrete toxidrome. Many do increase serotonergic transmission resulting in stimulatory effects, including tachycardia and hypertension. Agitation and neuropsychiatric symptoms predominate with these agents.

\section{Salvia}

Native to Oaxaca, Mexico, Salvia divinorum is a leafy plant of the mint family that has been long recognized for its psychoactive properties when inhaled or sublingually absorbed. ${ }^{100}$ Salvia is not currently controlled at a federal level in the USA, although it is banned by several individual states. ${ }^{100,101}$ The active component in salvia is the chemical salvinorin A, a strong hallucinogen with potency similar to LSD but a mechanism of action novel among the hallucinogens, acting at $\kappa$-opioid receptors. ${ }^{102}$ The subjective effects of salvia have been variably described, with some likening it to LSD but others to a very strong cannabis intoxication. ${ }^{47,103}$ Salvia intoxication has a quick onset, within 30 seconds, and a total duration of hallucinogenic effects lasting usually $<10$ minutes. ${ }^{104}$

There is a lack of reports of salvia intoxication resulting in any serious physiologic toxicity. ${ }^{47}$ A 10 -year survey of a major poison control system's experience with salvia intoxications showed that most patients reporting sole salvia ingestions required only simple monitoring. ${ }^{105}$ Patients in this survey who presented with clinical instability or persistently altered mental status were usually under the influence of other concurrent intoxicants, in one case a suspected belladonna alkaloid ingestion. ${ }^{105}$ If a patient reports salvia intoxication and becomes unstable or dramatically altered over time, one should suspect coingestion of other toxic substances or possible concurrent medical or psychiatric illness.

\section{Lysergic acid hydroxyethylamide (LSA) plants}

A 5-HT $\mathrm{HA}_{2 \mathrm{~A}}$ agonist, LSA is a naturally occurring hallucinogen that is chemically related to LSD and about onetenth as potent. ${ }^{106}$ LSA can be found in the seeds of the ornamental plants Ipomoea violacea (morning glory) and Argyreia nervosa (Hawaiian baby woodrose). Although seeds are often treated with an emetic by seed producers in order to discourage abuse, morning glory and woodrose seeds have been long abused as a legally available LSD substitute. ${ }^{106}$ After ingestion of crushed seeds, onset of hallucinogenic effects usually occurs within 1 hour and can last up to 10 hours. ${ }^{106}$

Major side effects include nausea, vomiting, and abdominal discomfort, which are thought to limit the abuse potential of LSA-containing seeds. ${ }^{107}$ Fatalities are rare, and those reported are usually secondary to self-harm due to acute agitation. ${ }^{108}$ In addition to producing hallucinogenic effects and agitation, the LSA-containing plants have been known to produce tachycardia, hypertension, pupillary dilation, flushing and polyuria. ${ }^{108}$ In the ED, suspected ingestion can 
be managed through sensory isolation and benzodiazepines as needed. ${ }^{109}$

\section{Synthetic cannabinoids}

With street names such as K2 and "Spice," the synthetic cannabinoids (SCs) are a heterogeneous and continually growing group of chemicals designed to produce the effects of the prototypical chemical tetrahydrocannabinol (THC) by acting on cannabinoid receptors. ${ }^{110}$ Given they usually share little to no similarity with THC, almost all will escape detection through standard urine toxicology screens. ${ }^{110}$ Many have been added to Schedule I. ${ }^{111}$ However, illicit drug manufacturers continue to design new analogs to escape existing regulations. ${ }^{110}$ The chemicals in liquid form are typically spread onto plant material that is then smoked or ingested, consumed outright, or vaporized and inhaled through electronic cigarettes. ${ }^{110}$

SCs are chemically heterogeneous but what they have in common is their affinity for cannabinoid receptors. ${ }^{112}$ A major difference between the SCs and the psychoactive compounds found in cannabis is in their relative affinity for cannabinoid receptors. Unlike marijuana, which contains over 50 known psychoactive chemicals, many of which have attenuating effects on THC, which is itself a partial agonist of cannabinoid receptors, many of the SCs are full agonists that demonstrate a much stronger affinity for these target receptors. ${ }^{112}$ It has been hypothesized that this is why, while marijuana results in little overt toxicity, many of the SCs have been found to have marked toxic effects, including excited delirium, seizures, psychosis, cardiotoxic effects, kidney injury, coma, and death. ${ }^{110}$ According to 1 survey of cannabis and synthetic cannabinoid users, users of SCs were much more likely to seek medical care for their symptoms. ${ }^{13}$ The risk of agitation and cardiotoxicity exceeds cannabis by 3.8 and 9.2 times, respectively. ${ }^{114}$

Physical examination findings of those using SCs have been found to be similar to those with cannabis intoxication, with delayed pupillary light reactions, slurred speech, and retarded sequence of movements. ${ }^{115}$ More severe clinical presentations may present with nausea and vomiting, abdominal pain, and excited delirium. Cases of rhabdomyolysis, acute kidney injury, and even myocardial infarction have been reported. ${ }^{115}$ SCs have also been associated with new onset refractory status epilepticus. ${ }^{116}$ There have also been emerging cases of arterial thromboemboli in otherwise healthy young people using SCs. ${ }^{117}$ Management centers around control of the excited delirium state as well as management of end-organ damage. ${ }^{115}$ Effects usually last around 8 hours for most of the chemicals in question. ${ }^{115}$

\section{Ayahuasca}

Ayahuasca, also known as hoasca, yage, and natema, is a hallucinogenic tea brewed traditionally among Amazonian tribes for religious purposes from the jungle vine Banisteriopsis caapi together with the leaves of the Psychotria viridis plant. ${ }^{118} P$. viridis contains most of the hallucinogenic activity through the compound $N, N$-dimethyltryptamine (DMT), a potent 5-HT agonist similar to LSD. ${ }^{119}$ By itself, DMT by oral ingestion is inactivated due to first pass metabolism by GI MAO. ${ }^{119}$ However, when combined with MAO-inhibiting beta-carboline alkaloids found in B. caapi, enough DMT is absorbed to produce psychedelic effects. ${ }^{119}$ The number of ayahuasca exposures has risen in the last 10 years in the USA, with a peak in 2012 at around 100 reported exposures. ${ }^{120}$ Although DMT is a Schedule I drug, and people have been prosecuted for possessing ayahuasca preparations, the plants themselves remain uncontrolled and legal to possess. ${ }^{120}$

The most common clinical manifestations of ayahuasca intoxication as reported to poison centers were hallucinations, tachycardia, agitation, hypertension, mydriasis, and vomiting. ${ }^{120}$ Altered mental status requiring intubation, seizures, and a few fatalities have been reported. ${ }^{120}$ Case reports of fatalities are limited by lack of forensic and toxicologic information, but some experts have suggested possible dangerous effects, including serotonin syndrome between ayahuasca and other serotonergic drugs such as prescription MAOIs and SSRIs. ${ }^{121}$ Treatment of ayahuasca intoxications consists of symptomatic supportive care and benzodiazepines for agitation or anxiety. ${ }^{120}$

\section{Kava kava}

Kava refers to a traditional beverage prepared from the tropical shrub plant Piper methysticum, native to the South Pacific. Used for centuries for its euphoric and anxiolytic effects, kava has seen increased use in the USA, where it is considered a health supplement. ${ }^{122}$ Kava is prepared typically by mixing crushed root or prepared extracts or powders with water or coconut milk, and it is also taken in pill form. ${ }^{123}$ The psychoactive components of kava are thought to be a group of lipophilic substances known as the kavalactones that exert their effects through numerous possible mechanisms ranging from enhanced GABA receptor binding to reversible inhibition of MAO B. ${ }^{124}$ 
Reports of acute kava toxicity resulting in adverse events requiring medical care are rare, accounting for 20 cases reported nationally in 2015. ${ }^{76,125,126}$ Reported adverse events include headaches, dyspnea, nausea, as well as dizziness, for which treatment is supportive. ${ }^{127,128}$ There have been reports of neurologic toxicity in the form of acute ataxia as well as dystonic reactions responsive to anticholinergics. ${ }^{129,130}$ Kava has been shown to have more profound acute mental status depressive effects when combined with benzodiazepines and alcohol. ${ }^{126,131,132}$ Excessive use of kava over a long term has been associated with cases of hepatotoxicity resulting in fulminant liver failure. ${ }^{133}$ Laboratory findings in chronic kava users have shown elevated liver enzymes, as well as lower blood lymphocyte counts. ${ }^{134}$ Physical exam findings in chronic kava users include skin photosensitivity, which usually resolves after cessation of use. ${ }^{135}$

\section{Inhalants}

Long abused as readily available "legal highs," inhalants refer to a heterogeneous group of usually lipophilic chemicals that are inhaled for their immediate consciousness-altering effects. ${ }^{136}$ Inhalants are most commonly abused among adolescents, and the most common types of abused chemicals include the volatile hydrocarbons found in widely available products such as air fresheners, paint, gasoline, adhesives, and propellants. ${ }^{137}$ The major non-hydrocarbon inhalant of abuse is nitrous oxide, which is found in whipped cream recharging canisters. ${ }^{136}$ According to available surveys, reports of abuse of volatile hydrocarbons seem to be decreasing, ${ }^{137}$ while reports of abuse of nitrous oxide seem to be increasing. ${ }^{138}$ In 1 survey, the inhalants with the highest reported mortality included nitrous oxide, butane, propane, and air fresheners. ${ }^{137}$

Patients abusing inhalants may present with a wide variety of subjective complaints, including dyspnea, palpitations, lightheadedness, sneezing and coughing, as well as GI complaints, including nausea and vomiting. ${ }^{136}$ Odors may persist in the breath for several hours following inhalation. ${ }^{139}$ Patients may also present with acute airway compromise due to chemical injury from aerosolized substances. ${ }^{140}$ Other clinical presentations are myriad, and may include altered mental status, headaches, and GI disturbances. ${ }^{136}$

The inhalational hydrocarbons of abuse have numerous toxic effects on the body, with cardiotoxic, neurotoxic, hepatotoxic, and nephrotoxic effects having been reported. ${ }^{136}$ The most profound cardiotoxic effect of hydrocarbon inhalation includes what is known as sudden sniffing death syndrome, which is thought to be due to cardiac arrhythmias caused by a sudden catecholamine surge in the setting of volatile hydrocarbon-sensitized myocardium. ${ }^{139}$ Some patients with cardiac arrhythmias due to inhalants survive long enough to present to the ED. ${ }^{141}$ In this setting, propranolol and other beta blockers have been used as agents to decrease myocardial catecholamine sensitivity, which is thought to be the mechanism of inhalant cardiotoxicity. ${ }^{141}$ Toluene and other hydrocarbon inhalants are also thought to sometimes cause QTc prolongation and torsades de pointes, as well as myocarditis. ${ }^{142-144}$ Acute toluene inhalation has also been associated with marked metabolic derangements such as rhabdomyolysis and type 1 renal tubular acidosis, with hyperchloremia, hypokalemia, and a normal anion gap. ${ }^{143}$

Besides possible acute fatal asphyxiation and even barotrauma from inhalation, the major toxic effects of nitrous oxide, aka "whippets" as they are known, are neurologic. Nitrous oxide inactivates vitamin B12, decreasing conversion of homocysteine to methionine, ultimately resulting in demyelination within the central and peripheral nervous systems. ${ }^{145}$ This classically results in subacute combined degeneration, especially around the dorsal columns of the spinal cord. ${ }^{145}$ Clinically, chronic nitrous oxide abuse may present with peripheral neuropathic effects, including tingling and numbness all the way up to loss of dexterity, poor balance, and leg weakness. ${ }^{146}$ Although the neurologic changes may be irreversible, some function may be restored through cessation and B12 supplementation. ${ }^{136}$

\section{Conclusion}

Existing outside of regulatory drug statutes, the drugs that can be used by patients to get "legal highs" truly represents an astounding array of chemicals, some of which are quite easily obtainable. "Legal highs" can represent a challenge to the emergency medicine physician due to the sheer number of available agents, their multiple toxidromes and presentations, their escaping traditional methods of analysis, and the reluctance of patients to divulge their use of these agents. However, a focus on aggressive symptombased supportive care is the mainstay of treatment for these patients in the ED.

\section{Disclosure}

The authors report no conflicts of interest in this work.

\section{References}

1. Musselman ME, Hampton JP. "Not for human consumption": a review of emerging designer drugs. Pharmacotherapy. 2014;34(7):745-757. 
2. Esters of Morphine. In: UNODC, ed. United Nations; 1953:36-38.

3. Thomas A, Nallur DG, Jones N, Deslandes PN. Diphenhydramine abuse and detoxification: a brief review and case report. $J$ Psychopharmacol. 2009;23(1):101-105.

4. Dilsaver SC. Antimuscarinic agents as substances of abuse - a review. J Clin Psychopharm. 1988;8(1):14-22.

5. Glatstein M, Alabdulrazzaq F, Scolnik D. Belladonna Alkaloid Intoxication: the 10-year experience of a large tertiary care pediatric hospital. Am J Ther. 2016;23(1):e74-e77.

6. Diker D, Markovitz D, Rothman M, Sendovski U. Coma as a presenting sign of Datura stramonium seed tea poisoning. Eur J Intern Med. 2007;18(4):336-338.

7. Krenzelok EP. Aspects of Datura poisoning and treatment. Clin Toxicol (Phila). 2010;48(2):104-110.

8. Krenzelok EP, Jacobsen TD, Aronis JM. Jimsonweed (Datura stramonium) poisoning and abuse. J Toxicol Clin Toxicol. 1995;40:303-304.

9. Feldman MD, Behar M. A case of massive diphenhydramine abuse and withdrawal from use of the drug. JAMA. 1986;255(22):3119-3120.

10. Crouch BI, Caravati EM, Booth J. Trends in child and teen nonprescription drug abuse reported to a regional poison control center. $\mathrm{Am}$ J Health-Syst Ph. 2004;61(12):1252-1257.

11. Wang GS, Monte A, Bagdure D, Heard K. Hepatic failure despite early acetylcysteine following large acetaminophen-diphenhydramine overdose. Pediatrics. 2011;127(4):e1077-e1080.

12. Koppel C, Ibe K, Tenczer J. Clinical symptomatology of diphenhydramine overdose: an evaluation of 136 cases in 1982 to 1985. J Toxicol Clin Toxicol. 1987;25(1-2):53-70.

13. Ramachandran K, Sirop P. Rare complications of diphenhydramine toxicity. Conn Med. 2008;72(2):79-82.

14. Krenzelok EP, Anderson GM, Mirick M. Massive diphenhydramine overdose resulting in death. Ann Emerg Med. 1982;11(4):212-213.

15. Li K, Gugelmann H, Tabas JA. Ecg of the month. Ann Emerg Med. 2015;66(4):363.

16. Tomassoni AJ, Weisman RS. Antihistamines and Decongestants. Goldfrank's Toxicologic Emergencies. 9th ed. New York, NY: McGraw Hill; 2011.

17. Benowitz I, Cohen AR, Glykys JC, Gorstein SV, Burns MM, Miller ES. An Altered, Unresponsive Teenager in the Emergency Department. J Emerg Med. 2016;50(1):116-120.

18. Abdi A, Rose E, Levine M. Diphenhydramine overdose with intraventricular conduction delay treated with hypertonic sodium bicarbonate and i.v. lipid emulsion. West J Emerg Med. 2014;15(7):855-858.

19. Quin GI, Fanning NF, Plunkett PK. Nutmeg intoxication. J Accid Emerg Med. 1998;15(4):287-288.

20. Williams EY, West F. The use of nutmeg as a psychotrpic drug. Report of two cases. J Natl Med Assoc. 1968;60(4):289-290.

21. Forrester MB. Nutmeg intoxication in Texas, 1998-2004. Hum Exp Toxicol. 2005;24(11):563-566

22. Carstairs SD, Cantrell FL. The spice of life: an analysis of nutmeg exposures in California. Clin Toxicol (Phila). 2011;49(3):177-180.

23. Ehrenpreis JE, DesLauriers C, Lank P, Armstrong PK, Leikin JB. Nutmeg poisonings: a retrospective review of 10 years experience from the Illinois Poison Center, 2001-2011.J Med Toxicol. 2014;10(2):148-151.

24. Halcomb S. Essential Oils. In: Nelson LS, Lewin NA, Howland MA, Hoffman RS, Goldfrank L, Flomenbaum N, editors. Goldfrank's Toxicologic Emergencies. 9th ed. New York, NY: McGrawHill; 2011:1.

25. Truitt EB Jr, Duritz G, Ebersberger EM. Evidence of monoamine oxidase inhibition by myristicin and nutmeg. Proc Soc Exp Biol Med. 1963;112:647-650.

26. Braun U, Kalbhen DA. Evidence for the biogenic formation of amphetamine derivatives from components of nutmeg. Pharmacology. 1973;9(5):312-316.

27. Ahmad A, Thompson HS. Nutmeg mydriasis. JAMA. 1975;234(3):274.

28. Michelot D, Melendez-Howell LM. Amanita muscaria: chemistry, biology, toxicology, and ethnomycology. Mycol Res. 2003;107(Pt 2):131-146.
29. Goldfrank L. Mushrooms. In: Nelson LS, Lewin NA, Howland MA, Hoffman RS, Goldfrank L, Flomenbaum N, editors. Goldfrank's Toxicologic Emergencies. 9th ed. New York, NY: McGrawHill; 2011:1528.

30. Halpern JH. Hallucinogens and dissociative agents naturally growing in the United States. Pharmacol Ther. 2004;102(2):131-138.

31. Satora L, Pach D, Butryn B, Hydzik P, Balicka-Slusarczyk B. Fly agaric (Amanita muscaria) poisoning, case report and review. Toxicon. 2005;45(7):941-943.

32. Nelson LS, Juurlink DN, Perrone J. Addressing the opioid epidemic. JAMA. 2015;314(14):1453-1454.

33. Taibbi M. If kratom helps opioid addicts, why might DEA outlaw it?: PBS Newshour; 2017.

34. MacDonald R, Heiner J, Villarreal J, Strote J. Loperamide dependence and abuse. BMJ Case Rep. 2015;2015.

35. Miller H, Panahi L, Tapia D, Tran A, Bowman JD. Loperamide misuse and abuse. J Am Pharm Assoc (2003). 2017;57(2S):S45-S50.

36. Daniulaityte R, Carlson R, Falck R, et al. "I just wanted to tell you that loperamide WILL WORK": a web-based study of extra-medical use of loperamide. Drug Alcohol Depend. 2013;130(1-3):241-244.

37. Wu PE, Juurlink DN. Clinical review: loperamide toxicity. Ann Emerg Med. 2017;70(2):245-252.

38. Swank KA, Wu E, Kortepeter C, McAninch J, Levin RL. Adverse event detection using the FDA post-marketing drug safety surveillance system: cardiotoxicity associated with loperamide abuse and misuse. J Am Pharm Assoc (2003). 2017;57(2S):S63-S67.

39. Pelders MG, Ros JJ. Poppy seeds: differences in morphine and codeine content and variation in inter- and intra-individual excretion. J Forensic Sci. 1996;41(2):209-212.

40. Braye K, Harwood T, Inder R, Beasley R, Robinson G. Poppy seed tea and opiate abuse in New Zealand. Drug Alcohol Rev. 2007;26(2):215-219.

41. Bailey K, Richards-Waugh L, Clay D, Gebhardt M, Mahmoud H, Kraner JC. Fatality involving the ingestion of phenazepam and poppy seed tea. J Anal Toxicol. 2010;34(8):527-532.

42. Nanjayya SB, Murthy P, Chand PK, et al. A case of poppy tea dependence in an octogenarian lady. Drug Alcohol Rev. 2010;29(2): 216-218.

43. Prozialeck WC. Update on the pharmacology and legal status of Kratom. J Am Osteopath Assoc. 2016;116(12):802-809.

44. Fluyau D, Revadigar N. Biochemical benefits, diagnosis, and clinical risks evaluation of Kratom. Front Psychiatry. 2017;8:62.

45. Kelly D. Lifesaving medicine or deadly drug?; Kratom, a plant used to treat addiction, gets a reprieve from DEA. Los Angeles Times. 2016 [October 20]; A8. Available from: https://www.pressreader.com/usa/ los-angeles-times/20161020/281625304835034. Accessed May 15, 2017.

46. Suwanlert S. A study of kratom eaters in Thailand. Bull Narc. 1975;27(3):21-27.

47. Babu KM, McCurdy CR, Boyer EW. Opioid receptors and legal highs: Salvia divinorum and Kratom. Clin Toxicol (Phila). 2008;46(2): $146-152$.

48. Kronstrand R, Roman M, Thelander G, Eriksson A. Unintentional fatal intoxications with mitragynine and O-desmethyltramadol from the herbal blend Krypton. J Anal Toxicol. 2011;35(4):242-247.

49. Neerman MF, Frost RE, Deking J. A drug fatality involving Kratom. J Forensic Sci. 2013;58 (Supp1 1):S278-S279.

50. McIntyre IM, Trochta A, Stolberg S, Campman SC. Mitragynine 'Kratom' related fatality: a case report with postmortem concentrations. J Anal Toxicol. 2015;39(2):152-155.

51. Helander A, Backberg M, Beck O. MT-45, a new psychoactive substance associated with hearing loss and unconsciousness. Clin Toxicol (Phila). 2014;52(8):901-904.

52. Siddiqi S, Verney C, Dargan P, Wood DM. Understanding the availability, prevalence of use, desired effects, acute toxicity and dependence potential of the novel opioid MT-45. Clin Toxicol (Phila). 2015;53(1):54-59. 
53. Lozier MJ, Boyd M, Stanley C, et al. Acetyl fentanyl, a novel fentanyl analog, causes 14 overdose deaths in rhode island, March-May 2013. J Med Toxicol. 2015;11(2):208-217.

54. Drug Enforcement Administration DoJ. Emerging Threat Report: 2016 Report. In: Laboratory STaR, ed; 2017.

55. Schumann H, Erickson T, Thompson TM, Zautcke JL, Denton JS. Fentanyl epidemic in Chicago, Illinois and surrounding Cook County. Clin Toxicol (Phila). 2008;46(6):501-506.

56. Valente MJ, Guedes de Pinho P, de Lourdes Bastos M, Carvalho F, Carvalho M. Khat and synthetic cathinones: a review. Arch Toxicol. 2014;88(1):15-45.

57. Prosser JM, Nelson LS. The toxicology of bath salts: a review of synthetic cathinones. J Med Toxicol. 2012;8(1):33-42.

58. American Association of Poison Control Centers. Bath Salts Data. 2016 March 31. Available from: https://aapcc.s3.amazonaws.com/files/library/ Bath_Salts_Web_Data_through_3.2016.pdf. Accessed May 15, 2017.

59. Drug Enforcement Administration, DoJ. Schedules of controlled substances: placement of 10 synthetic cathinones into schedule I. Final rule. Fed Regist. 2017;82(39):12171-12177.

60. Nugteren-van Lonkhuyzen JJ, van Riel AJ, Brunt TM, Hondebrink L. Pharmacokinetics, pharmacodynamics and toxicology of new psychoactive substances (NPS): 2C-B, 4-fluoroamphetamine and benzofurans. Drug Alcohol Depend. 2015;157:18-27.

61. Zawilska JB, Andrzejczak D. Next generation of novel psychoactive substances on the horizon - A complex problem to face. Drug Alcohol Depend. 2015;157:1-17.

62. Hofer KE, Faber K, Muller DM, et al. Acute toxicity associated with the recreational use of the novel psychoactive benzofuran N-methyl-5-(2 aminopropyl)benzofuran. Ann Emerg Med. 2017;69(1):79-82.

63. Corazza O, Schifano F, Farre M, et al. Designer drugs on the internet: a phenomenon out-of-control? the emergence of hallucinogenic drug Bromo-Dragonfly. Curr Clin Pharmacol. 2011;6(2):125-129.

64. Coppola M, Mondola R. Bromo-DragonFly: chemistry, pharmacology and toxicology of a Benzodifuran derivative producing LSD-like effects. J Add Res Ther. 2012;3(4):133.

65. Chavarin A, Nogue S, Castaneda-Pomeda M, Gil V. The dangers of buying "research chemicals" online, bromo-dragonfly mislabelled as 2C-B Fly: a confirmed case report, and its follow up in "research chemical” specific social media. Clin Toxicol. 2013;51(4):347-347.

66. Wood DM, Looker JJ, Shaikh L, et al. Delayed onset of seizures and toxicity associated with recreational use of Bromo-dragonFLY. J Med Toxicol. 2009;5(4):226-229.

67. Personae M, Hulten P. Bromo-Dragonfly, a life threatening designer drug. Clin Toxicol. 2008;46(5):379-380.

68. Andreasen MF, Telving R, Birkler RI, Schumacher B, Johannsen M. A fatal poisoning involving Bromo-Dragonfly. Forensic Sci Int. 2009; 183(1-3):91-96.

69. Liggett SB. Propylhexedrine Intoxication: clinical presentation and pharmacology. South Med J. 1982;75(2):250-251.

70. Anderson RJ, Garza HR, Garriott JC, Dimaio V. Intravenous propylhexedrine (Benzedrex) abuse and sudden-death. Am J Med. 1979;67(1):15-20.

71. Fernandez Julia P, Francis EM. Propylhexedrine: a vintage drug of abuse, rediscovered. J Psychoactive Drugs. 2012;44(3):277-279.

72. Marsden P, Sheldon J. Acute poisoning by propylhexedrine. Br Med J. 1972;1(5802):730.

73. Fornazzari L, Carlen PL, Kapur BM. Intravenous abuse of propylhexedrine (Benzedrex) and the risk of brainstem dysfunction in young adults. Can J Neurol Sci. 1986;13(4):337-339.

74. White L, DiMaio VJ. Intravenous propylhexedrine and sudden death. N Engl J Med. 1977;297(19):1071.

75. Carstairs SD, Cantrell FL. Peyote and mescaline exposures: a 12-year review of a statewide poison center database. Clin Toxicol (Phila). 2010;48(4):350-353.

76. Mowry JB, Spyker DA, Brooks DE, Zimmerman A, Schauben JL. 2015 Annual Report of the American Association of Poison Control Centers' National Poison Data System (NPDS): 33rd Annual Report. Clin Toxicol (Phila). 2016;54(10):924-1109.
77. Teitelbaum DT, Wingeleth DC. Diagnosis and management of recreational mescaline self poisoning. JAnalytical Toxicol. 1977;1(1):36-37.

78. Administration DE. Schedules of controlled substances: placement of Ketamine into schedule III. In: Justice Do, ed1999.

79. Winstock AR, Lawn W, Deluca P, Borschmann R. Methoxetamine: an early report on the motivations for use, effect profile and prevalence of use in a UK clubbing sample. Drug Alcohol Rev. 2016;35(2):212-217.

80. Backberg M, Beck O, Helander A. Phencyclidine analog use in Sweden-intoxication cases involving 3-MeO-PCP and 4-MeO-PCP from the STRIDA project. Clin Toxicol. 2015;53(9):856-864.

81. Elliott SP, Brandt SD, Wallach J, Morris H, Kavanagh PV. First reported fatalities associated with the 'research chemical' 2-methoxydiphenidine. J Anal Toxicol. 2015;39(4):287-293.

82. Wallach J, Kang H, Colestock T, et al. Pharmacological Investigations of the Dissociative 'Legal Highs' Diphenidine, Methoxphenidine and Analogs. PLoS One. 2016;11(6):e0157021.

83. Adamowicz P, Zuba D. Fatal intoxication with methoxetamine. $J$ Forensic Sci. 2015;60 (Suppl 1):S264-S268.

84. Helander A, Beck O, Backberg M. Intoxications by the dissociative new psychoactive substances diphenidine and methoxphenidine. Clin Toxicol (Phila). 2015;53(5):446-453.

85. Zawilska JB. Methoxetamine-a novel recreational drug with potent hallucinogenic properties. Toxicol Lett. 2014;230(3):402-407.

86. Majlesi N, Lee DC, Ali SS. Dextromethorphan abuse masquerading as a recurrent seizure disorder. Pediatr Emerg Care. 2011;27(3): 210-211.

87. Shafi H, Imran M, Usman HF, et al. Deaths due to abuse of dextromethorphan sold over-the-counter in Pakistan. Egypt J Forensic Sci. 2016;6(3):280-283.

88. Dextromethorphan (DXM); 2017. Available from: http://www.cesar umd.edu/cesar/drugs/dxm.asp\#history. Accessed April 20, 2017

89. Chyka PA, Erdman AR, Manoguerra AS, et al. Dextromethorphan poisoning: an evidence-based consensus guideline for out-of-hospital management. Clin Toxicol (Phila). 2007;45(6):662-677.

90. Stanciu CN, Penders TM, Rouse EM. Recreational use of dextromethorphan, "Robotripping"-A brief review. Am JAddict. 2016;25(5):374-377.

91. Cunningham V. Dextromethorphan abuse in teens: beware acetaminophen poisoning! CJEM. 2011;13(5):298.

92. Justice UDo. Intelligence Bulletin: DXM (Dextromethorphan); 2004. Avaialble from: https:/www.justice.gov/archive/ndic/pubs11/11,563/. Accessed April 20, 2017.

93. Hendrickson RG, Cloutier RL. "Crystal dex:" free-base dextromethorphan. J Emerg Med. 2007;32(4):393-396.

94. Boyer EW. Dextromethorphan abuse. Pediatr Emerg Care. 2004;20(12):858-863.

95. Schneider SM, Michelson EA, Boucek CD, Ilkhanipour K. Dextromethorphan poisoning reversed by naloxone. Am J Emerg Med. 1991;9(3):237-238.

96. Antoniou T, Juurlink DN. Dextromethorphan abuse. CMAJ. 2014;186(16):E631.

97. Wolfe TR, Caravati EM. Massive dextromethorphan ingestion and abuse. Am J Emerg Med. 1995;13(2):174-176.

98. Ng YY, Lin WL, Chen TW, et al. Spurious hyperchloremia and decreased anion gap in a patient with dextromethorphan bromide. Am J Nephrol. 1992;12(4):268-270.

99. Hung YM. Bromide intoxication by the combination of bromidecontaining over-the-counter drug and dextromethorphan hydrobromide. Hum Exp Toxicol. 2003;22(8):459-461.

100. Babu KM. Hallucinogens. In: Nelson LS, Lewin NA, Howland MA, Hoffman RS, Goldfrank L, Flomenbaum N, editors. Goldfrank's Toxicologic Emergencies. 9th ed. New York, NY: McGraw Hill; 2011.

101. Prisinzano TE. Psychopharmacology of the hallucinogenic sage Salvia divinorum. Life Sci. 2005;78(5):527-531.

102. Sheffler DJ, Roth BL. Salvinorin A: the "magic mint" hallucinogen finds a molecular target in the kappa opioid receptor. Trends Pharmacol Sci. 2003;24(3):107-109.

103. Albertson DN, Grubbs LE. Subjective effects of Salvia divinorum: LSD- or marijuana-like? J Psychoactive Drugs. 2009;41(3):213-217. 
104. Johnson LA, Johnson RL, Portier RB. Current "legal highs". J Emerg Med. 2013;44(6):1108-1115.

105. Vohra R, Seefeld A, Cantrell FL, Clark RF. Salvia divinorum: exposures reported to a statewide poison control system over 10 years. J Emerg Med. 2011;40(6):643-650.

106. Richardson WH, 3rd, Slone CM, Michels JE. Herbal drugs of abuse: an emerging problem. Emerg Med Clin North Am. 2007;25(2):435-457.

107. Juszczak GR, Swiergiel AH. Recreational use of D-Lysergamide from the seeds of Argyreia nervosa, Ipomoea tricolor, Ipomoea violacea, and Ipomoea purpurea in Poland. J Psychoactive Drugs. 2013;45(1):79-93.

108. Klinke HB, Muller IB, Steffenrud S, Dahl-Sorensen R. Two cases of lysergamide intoxication by ingestion of seeds from Hawaiian Baby Woodrose. Forensic Sci Int. 2010;197(1-3):E1-E5.

109. Nelson ME, Bryant SM, Aks SE. Emerging drugs of abuse. Dm-Dis Mon. 2014;60(3):110-132.

110. Trecki J, Gerona RR, Schwartz MD. Synthetic cannabinoid-related illnesses and deaths. N Engl J Med. 2015;373(2):103-107.

111. Drug Enforcement Administration DoJ. Schedules of Controlled Substances: Temporary Placement of Six Synthetic Cannabinoids (5F-ADB, 5F-AMB, 5F-APINACA, ADB-FUBINACA, MDMBCHMICA and MDMB-FUBINACA) into Schedule I. Temporary Scheduling Order. Fed Regist. 2017;82(67):17119-17124.

112. Baumeister D, Tojo LM, Tracy DK. Legal highs: staying on top of the flood of novel psychoactive substances. Ther Adv Psychopharmacol. 2015;5(2):97-132.

113. Winstock A, Lynskey M, Borschmann R, Waldron J. Risk of emergency medical treatment following consumption of cannabis or synthetic cannabinoids in a large global sample. J Psychopharmacol. 2015;29(6):698-703.

114. Martinotti G, Santacroce R, Papanti D, Elgharably Y, Prilutskaya M, Corazza O. Synthetic Cannabinoids: psychopharmacology, clinical aspects, and psy-chotic onset. CNS Neurol Disord Drug Targets. 2017;16(5):567-575

115. Phillips J, Lim F, Hsu R. The emerging threat of synthetic cannabinoids. Nurs Manage. 2017;48(3):22-30.

116. Patel NA, Jerry JM, Jimenez XF, Hantus ST. New-Onset Refractory Status Epilepticus Associated With the Use of Synthetic Cannabinoids. Psychosomatics. 2017;58(2):180-186.

117. Raheemullah A, Laurence TN. Repeated thrombosis after synthetic cannabinoid use. J Emerg Med. 2016;51(5):540-543.

118. Cunningham N. Hallucinogenic plants of abuse. Emerg Med Australas. 2008;20(2):167-174.

119. Riba J, Valle M, Urbano G, Yritia M, Morte A, Barbanoj MJ. Human pharmacology of ayahuasca: Subjective and cardiovascular effects, monoamine metabolite excretion, and pharmacokinetics. J Pharmacol Exp Ther. 2003;306(1):73-83.

120. Heise CW, Brooks DE. Ayahuasca exposure: descriptive analysis of calls to US poison control centers from 2005 to 2015. J Med Toxicol. Epub 2016 Nov 28.

121. dos Santos RG. A critical evaluation of reports associating ayahuasca with life-threatening adverse reactions. $J$ Psychoactive Drugs. 2013;45(2):179-188.

122. Kava. In: Drug Enforcement Administration DoJ, editor. Washington, DC; 2013.

123. Fu PP, Xia Q, Guo L, Yu H, Chan PC. Toxicity of kava kava. J Environ Sci Health C Environ Carcinog Ecotoxicol Rev. 2008;26(1):89-112.

124. Sarris J, LaPorte E, Schweitzer I. Kava: a comprehensive review of efficacy, safety, and psychopharmacology. Aust $N Z J$ Psychiatry. 2011;45(1):27-35.

125. Bent S, Tiedt TN, Odden MC, Shlipak MG. The relative safety of ephedra compared with other herbal products. Ann Intern Med. 2003;138(6):468-471.
126. Lai MW, Klein-Schwartz W, Rodgers GC, et al. 2005 Annual Report of the American Association of Poison Control Centers' national poisoning and exposure database. Clin Toxicol (Phila). 2006;44(6-7): 803-932.

127. Dennehy CE, Tsourounis C, Horn AJ. Dietary supplement-related adverse events reported to the California Poison Control System. Am $J$ Health Syst Pharm. 2005;62(14):1476-1482.

128. Wheatley D. Stress-induced insomnia treated with kava and valerian: singly and in combination. Hum Psychopharmacol. 2001;16(4): 353-356.

129. Perez J, Holmes JF. Altered mental status and ataxia secondary to acute Kava ingestion. J Emerg Med. 2005;28(1):49-51.

130. Schelosky L, Raffauf C, Jendroska K, Poewe W. Kava and dopamine antagonism. J Neurol Neurosurg Psychiatry. 1995;58(5):639-640.

131. Almeida JC, Grimsley EW. Coma from the health food store: interaction between kava and alprazolam. Ann Intern Med. 1996;125(11):940-941.

132. Foo H, Lemon J. Acute effects of kava, alone or in combination with alcohol, on subjective measures of impairment and intoxication and on cognitive performance. Drug Alcohol Rev. 1997;16(2): $147-155$.

133. Teschke R, Schwarzenboeck A, Hennermann KH. Kava hepatotoxicity: a clinical survey and critical analysis of 26 suspected cases. Eur J Gastroenterol Hepatol. 2008;20(12):1182-1193.

134. Cairney S, Maruff P, Clough AR, Collie A, Currie J, Currie BJ. Saccade and cognitive impairment associated with kava intoxication. Hum Psychopharmacol. 2003;18(7):525-533.

135. Hannam S, Murray M, Romani L, Tuicakau M, M JW. Kava dermopathy in Fiji: an acquired ichthyosis? Int J Dermatol. 2014;53(12): 1490-1494.

136. Long H. Inhalants. Goldfrank's Toxicologic Emergencies. 9th ed. New York, NY: McGraw-Hill Companies; 2011:1187-1194.

137. Marsolek MR, White NC, Litovitz TL. Inhalant abuse: monitoring trends by using poison control data, 1993-2008. Pediatrics. 2010;125(5): 906-913.

138. van Amsterdam J, Nabben T, van den Brink W. Recreational nitrous oxide use: Prevalence and risks. Regul Toxicol Pharmacol. 2015;73(3):790-796.

139. Kurtzman TL, Otsuka KN, Wahl RA. Inhalant abuse by adolescents. J Adolesc Health. 2001;28(3):170-180.

140. Plumb J, Thomas RG. Sudden severe perioral swelling in an adolescent boy. Clin Toxicol (Phila). 2013;51(4):379-380.

141. Kopec KT, Brent J, Banner W, Ruha AM, Leikin JB. Management of cardiac dysrhythmias following hydrocarbon abuse: clinical toxicology teaching case from NACCT acute and intensive care symposium. Clin Toxicol (Phila). 2014;52(2):141-145.

142. Cates AL, Cook MD. Severe Cardiomyopathy after Huffing Dust-Off. Case Rep Emerg Med. 2016;2016:9204790.

143. Camara-Lemarroy CR, Rodriguez-Gutierrez R, Monreal-Robles R, Gonzalez-Gonzalez JG. Acute toluene intoxication-clinical presentation, management and prognosis: a prospective observational study. BMC Emerg Med. 2015;15:19.

144. Dinsfriend W, Rao K, Matulevicius S. Inhalant-abuse myocarditis diagnosed by cardiac magnetic resonance. Tex Heart Inst $J$. 2016;43(3):246-248.

145. Thompson AG, Leite MI, Lunn MP, Bennett DL. Whippits, nitrous oxide and the dangers of legal highs. Pract Neurol. 2015;15(3): 207-209.

146. Kaar SJ, Ferris J, Waldron J, Devaney M, Ramsey J, Winstock AR. Up: The rise of nitrous oxide abuse. An international survey of contemporary nitrous oxide use. J Psychopharmacol. 2016;30(4):395-401.

147 Galbis-Reig D. A case report of kratom addiction and withdrawal. WMJ. 2016;115(1):49-52. 
Open Access Emergency Medicine

\section{Publish your work in this journal}

The Open Access Emergency Medicine is an international, peerreviewed, open access journal publishing original research, reports, editorials, reviews and commentaries on all aspects of emergency medicine. The manuscript management system is completely online and includes a very quick and fair peer-review system, which is all

Submit your manuscript here: https://www.dovepress.com/open-access-emergency-medicine-journal

\section{Dovepress}

easy to use. Visit http://www.dovepress.com/testimonials.php to read real quotes from published authors. 